Cytogenet Genome Res 1973;12:295

\title{
Authors' erratum
}

In the article entitled "Further studies on a Robertsonian translocation in the Saanen dairy goat," by B. Padeh, M. Wisoki, and M. Soller (Cytogenetics 10: 61-69 [1971], certain data were omitted from table I. The corrected table appears below.

Table I. Distribution of translocation chromosome among offspring of heterozygous males by karyotype of female parent, type of birth, and sex of offspring. ${ }^{1}$

Female

Type

No.

of

birth

Karyotype of offspring

parent karyotype

Male 60

Female

$58+$ T $56+$ TT

60 
$2 \mathrm{~N}=60$

Singles Twin Twin Triplet

12

2

21

5

$2 \mathrm{~N}=58+\mathrm{T}$

Singles

Twin

Twin

Twin

Triplet

2

12

11

1

1

11

Single

Twin

Twin

1

2

Twins and triplets are shown separately. 